\title{
Effects of Supplemental Yeast (Saccharomyces cerevisiae) Culture on Rumen Development, Growth Characteristics, and Blood Parameters in Neonatal Dairy Calves
}

\author{
K. E. Lesmeister, A. J. Heinrichs, and M. T. Gabler \\ Department of Dairy and Animal Science, \\ The Pennsylvania State University, University Park 16802
}

\section{ABSTRACT}

Yeast (Saccharomyces cerevisiae) culture was added to a texturized calf starter at 0 (control), 1 , or $2 \%$ of dry matter to determine effects on intake, growth, blood parameters, and rumen development. Seventy-five Holstein calves (38 male; 37 female) were started on the experiment at $2 \pm 1 \mathrm{~d}$ of age and were studied for $42 \mathrm{~d}$. Starter intake was measured, and fecal scoring was conducted daily. Growth and blood parameter measurements were recorded at weekly intervals. A subset of 6 male calves ( 2 per treatment) was euthanized at 5 wk of age, and rumen tissue was sampled for rumen epithelial growth measurements. An additional 6 male calves were euthanized at 6 wk of age for rumen epithelial growth measurements. Inclusion of yeast culture at $2 \%$ of the starter ration significantly increased starter and total dry matter intake, average daily gain, and daily hip width change when compared with the control treatment. Average daily gain was improved by $15.6 \%$ for the $2 \%$ yeast treatment. Daily change in hip height was also significantly greater for calves receiving $2 \%$ supplemental yeast culture than for calves receiving $1 \%$. No significant treatment differences were observed for any other variables. These data suggest that the addition of yeast culture in a dairy calf starter at $2 \%$ enhances dry matter intake and growth and slightly improves rumen development in dairy calves.

(Key words: yeast culture, rumen development, calf)

Abbreviation key: ADG = average daily gain, $\mathbf{D S}=$ days scoured, FE = feed efficiency, HEM = blood hematocrit, $\mathbf{P L}=$ papillae length, $\mathbf{P T P}=$ plasma total protein, $\mathbf{P W}=$ papillae width, $\mathbf{R W T}=$ rumen wall thickness, $\mathbf{1 Y C}=1 \%$ yeast culture, $\mathbf{2 Y C}=2 \%$ yeast culture .

\section{INTRODUCTION}

Influences of yeast (Saccharomyces cerevisiae) culture supplementation on numerous growth and produc-

Received December 5, 2003.

Accepted December 22, 2003.

Corresponding author: A. J. Heinrichs; E-mail: ajh@psu.edu. tion traits have been studied in most ruminant age classes. However, results are somewhat inconsistent throughout the literature, partially because of confounding effects of ration composition, level of yeast culture inclusion, and source of yeast culture product tested (Williams et al., 1991). In addition, only a few studies have utilized pre-ruminant dairy calves (Wagner et al., 1990; Quigley et al., 1992; Seymour et al., 1995; Kumar et al., 1997). When brewer's yeast (Seymour et al., 1995) or live yeast (Wagner et al., 1990; Quigley et al., 1992) was included in calf diets at levels between $0.001 \%$ and $1.00 \%$, DMI, average daily gain (ADG), percentage of days scoured (DS), rumen ammonia, rumen lactic acid production, and ruminal propionate were either decreased or not affected. However, yeast culture has increased feed efficiency $(\mathbf{F E})$, rumen $\mathrm{pH}$, total ruminal VFA concentration, and ruminal butyrate and acetate production when included in calf diets (Quigley et al., 1992; Kumar et al., 1997). Williams et al. (1991) suggested that calf diet supplementation with yeast culture may increase rumen $\mathrm{pH}$ regulation via reduced lactic acid production.

Regulation of ruminal $\mathrm{pH}$ and reduced lactic acid production are of interest in rumen development research because of the influence of these parameters on intake and parakeratosis (Bull et al., 1965; Hinders and Owen, 1965). Furthermore, increased butyrate production, decreased lactic acid production, and, subsequently, increased rumen $\mathrm{pH}$ may synergistically influence neonatal calf rumen development (Flatt et al., 1958; Sander et al., 1959). However, the effects of supplemental yeast culture on rumen development have not been determined. Previous research also indicates yeast culture affects feed constituent digestibility, microbial production and efficiency, and AA flow to the duodenum (Erasmus et al., 1992; Mutsvangwa et al., 1992; Yoon and Stern, 1996). In addition, increased feed component digestibility via increased ruminal microbial production and efficiency may also influence butyrate production. Furthermore, increased microbial nitrogen flow and AA presentation to the duodenum may aid overall calf growth and development (Erasmus et 
al., 1992; Mutsvangwa et al., 1992; Yoon and Stern, 1996). It is hypothesized that yeast (Saccharomyces cerevisiae) culture inclusion in a dairy calf starter would aid rumen development and calf growth. Therefore, this trial was conducted to determine the effects of supplemental yeast culture in a dairy calf starter on rumen development, feed intake, structural growth, scour occurrences, and blood component concentrations.

\section{MATERIALS AND METHODS}

\section{Animals, Housing, and Diet}

Seventy-five Holstein calves (38 male; 37 female) were separated from their dams shortly after birth, randomly assigned by sex to a treatment, blocked by birth date ( 25 blocks per treatment), and placed on experiment at $2 \pm 1 \mathrm{~d}$ of age. Abrupt weaning occurred at $35 \pm 1 \mathrm{~d}$ of age; calves were maintained on the study until $42 \pm 1 \mathrm{~d}$ of age. Treatments consisted of a texturized calf starter containing $0 \%$ (control), $1 \%$ (1YC), or $2 \%$ (2YC) supplemental yeast culture as a percentage of starter DM (Diamond V XP Yeast Culture; Diamond V Mills, Inc., Cedar Rapids, IA). Calves were housed in a naturally and mechanically ventilated barn and kept in 1.2-m $\times 2.4-\mathrm{m}$ individual pens bedded with wood shavings. Nose-to-nose contact between calves was minimized by pen arrangement. All calves received 4 $\mathrm{L}$ of colostrum within $12 \mathrm{~h}$ of birth followed by 4 feedings of colostrum. Calves received a $20 \% \mathrm{CP}, 20 \%$ fat, and non-medicated milk replacer containing all-milk protein (Land O' Lakes Animal Milk Products Co., Arden Hills, MN; metabolizable energy $=4.75 \mathrm{Kcal} / \mathrm{kg} \mathrm{DM}$, [NRC, 2001]) from $3 \mathrm{~d}$ of age until weaning. Milk replacer was provided in 2 equal feedings at $10 \%$ of birth weight daily until abrupt weaning. Texturized calf starter was offered ad libitum, and intake was measured daily, beginning when calves were placed on the study. Water was provided free choice and changed $2 \times$ daily. Calves were cared for and maintained according to guidelines stipulated by The Pennsylvania State University Animal Care and Use Committee.

\section{Starter Nutrient Composition}

Starter samples were analyzed in duplicate for moisture (AOAC, 1990). Crude protein (AOAC, 2000) was analyzed using a Leco FP-528 Nitrogen Combustion Analyzer (Leco, St. Joseph, MI), and soluble CP was determined as described by Krishnamoorthy et al. (1982) where insoluble protein was recovered on 7-cm diameter filter paper and introduced into a Leco FP528 Nitrogen Combustion Analyzer for determination of CP (AOAC, 2000). Values for total digestible nutrients, net energy for maintenance, and net energy for
Table 1. Ingredient composition of texturized calf starter containing 0 (control), 1 (1YC), or $2 \%$ (2YC) supplemental yeast culture.

\begin{tabular}{|c|c|c|c|}
\hline & Control & $1 \mathrm{YC}$ & $2 \mathrm{YC}$ \\
\hline \multicolumn{4}{|l|}{ Ingredients, \% DM } \\
\hline Roasted corn & 33.29 & 32.29 & 31.29 \\
\hline Cane molasses & 5.08 & 5.08 & 5.08 \\
\hline Oats & 15.54 & 15.54 & 15.54 \\
\hline Yeast culture $^{1}$ & 0.00 & 1.00 & 2.00 \\
\hline \multicolumn{4}{|l|}{ Premix pellet } \\
\hline Wheat middlings & 17.09 & 17.09 & 17.09 \\
\hline Soybean meal & 23.92 & 23.92 & 23.92 \\
\hline Calcium carbonate & 2.35 & 2.35 & 2.35 \\
\hline Dicalcium phosphate & 1.26 & 1.26 & 1.26 \\
\hline Salt & 0.94 & 0.94 & 0.94 \\
\hline Vitamin A premix ${ }^{2}$ & 0.02 & 0.02 & 0.02 \\
\hline Vitamin B- $12^{3}$ & 0.001 & 0.001 & 0.001 \\
\hline $\operatorname{Deccox}^{4}$ & 0.06 & 0.06 & 0.06 \\
\hline Vitamin $\mathrm{E}^{5}$ & 0.009 & 0.009 & 0.009 \\
\hline Vitamin $D^{6}$ & 0.008 & 0.008 & 0.008 \\
\hline Magnesium oxide & 0.09 & 0.09 & 0.09 \\
\hline Riboflavin ${ }^{7}$ & 0.009 & 0.009 & 0.009 \\
\hline Selenium $^{8}$ & 0.11 & 0.11 & 0.11 \\
\hline Calcium propionate & 0.05 & 0.05 & 0.05 \\
\hline Trace mineral pre-mix & 0.016 & 0.016 & 0.016 \\
\hline Flavor & 0.16 & 0.16 & 0.16 \\
\hline
\end{tabular}

${ }^{1}$ Diamond V XP, Diamond V Mills, Inc., Cedar Rapids, IA.

${ }^{2} 81,250,000 \mathrm{IU} / \mathrm{kg}$.

${ }^{3} 136.2 \mathrm{mg} / \mathrm{kg}$.

${ }^{4}$ Decoquinate, Alpharma, Inc., Fort Lee, NJ.

${ }^{5} 103,058 \mathrm{IU} / \mathrm{kg}$.

${ }^{6} 44,000,000 \mathrm{IU} / \mathrm{kg}$.

${ }^{7} 16,500 \mathrm{mg} / \mathrm{kg}$.

${ }^{8} 0.06 \%$.

gain were calculated using the NRC (2001) model. Starter samples were analyzed for $\mathrm{NDF}, \mathrm{ADF}$, and crude fat (AOAC, 1990) using a Tecator Soxtec System HT 1043 Extraction unit (Tecator, Foss NA, Eden Prairie, MN). Heat stable $\alpha$-amylase (no. A3306; Sigma Chemical Co., St. Louis, MO) was included in the NDF procedure. Ash and mineral content were determined (AOAC, 1990) utilizing a Perkin Elmer 3300 XL ICP (Perkin Elmer, Shelton, CT). Values for non-fibrous carbohydrates were calculated as $100-(\% \mathrm{NDF}+\% \mathrm{CP}$ $+\%$ fat $+\%$ ash [NRC, 2001]). Calf starter ingredient and nutrient composition are presented in Tables 1 and 2 , respectively. By design, nutrient composition was similar between treatments with the exception of yeast culture content.

\section{Fecal Scoring and Experimental Measurements}

Fecal scoring for determination of fecal fluidity, consistency, odor, and DS was conducted daily utilizing the procedure of Larson et al. (1977). Scoring was as follows: for fecal fluidity, $1=$ normal, $2=$ soft, $3=$ runny, or 4 = watery; for fecal consistency, $1=$ normal, $2=$ foamy, 3 = mucous, 4 = sticky, or $5=$ constipated; and 
Table 2. Nutrient composition of texturized calf starter containing 0 (control), 1 (1YC), or $2 \%$ (2YC) supplemental yeast culture. ${ }^{1}$

\begin{tabular}{lccc}
\hline & Control & 1YC & 2 YC \\
\hline Nutrient & & & \\
DM, \% & 88.0 & 89.0 & 88.1 \\
CP, \% & 22.6 & 22.3 & 22.5 \\
Soluble CP, \% of CP & 16.8 & 18.0 & 17.0 \\
TDN, ${ }^{2} \%$ & 77.7 & 77.2 & 77.2 \\
$\mathrm{NE}_{\mathrm{M}}{ }^{3}$ Mcal/kg & 2.3 & 2.2 & 2.2 \\
$\mathrm{NE}_{\mathrm{G}}, \mathrm{Mcal} / \mathrm{kg}$ & 1.7 & 1.7 & 1.7 \\
$\mathrm{ADF}, \%$ & 7.8 & 8.7 & 8.8 \\
$\mathrm{NDF}, \%$ & 17.7 & 19.3 & 18.9 \\
Crude fat, \% & 3.0 & 3.0 & 3.4 \\
Ash, \% & 10.8 & 11.8 & 11.6 \\
NFC, $\%$ & 45.9 & 43.5 & 43.7 \\
Ca, \% & 1.89 & 2.04 & 1.99 \\
$\mathrm{P}, \%$ & 0.87 & 0.94 & 0.93 \\
$\mathrm{Mg}, \%$ & 0.43 & 0.42 & 0.39 \\
$\mathrm{~K}, \%$ & 1.41 & 1.38 & 1.42 \\
Na, \% & 0.32 & 0.45 & 0.33 \\
$\mathrm{Fe}, \mathrm{ppm}$ & 447 & 564 & 470 \\
$\mathrm{Mn}, \mathrm{ppm}$ & 116 & 117 & 107 \\
$\mathrm{Zn}, \mathrm{ppm}$ & 117 & 120 & 102 \\
$\mathrm{Cu}, \mathrm{ppm}$ & 21 & 19 & 16 \\
\hline
\end{tabular}

${ }^{1}$ All values are reported on a DM basis.

${ }^{2} \mathrm{TDN}=$ total digestible nutrients.

${ }^{3}$ Calculated using the NRC (2001) model. $\mathrm{NE}_{\mathrm{M}}=$ net energy for maintenance; $\mathrm{NE}_{\mathrm{G}}=$ net energy for gain.

${ }^{4} \mathrm{NFC}($ non-fiber carbohydrate $)=100-(\% \mathrm{NDF}+\% \mathrm{CP}+\%$ fat + $\%$ ash).

for fecal odor, 1 = normal, 2 = slightly offensive, or 3 = highly offensive. A scour day was recorded if fecal fluidity $=3$ or 4 , fecal consistency $=3$, and fecal odor $=$ 2 or 3 . Weekly measurements of BW, withers height, hip height, hip width, and heart girth were recorded. Blood samples $(25 \mathrm{~mL})$ were collected weekly at $4 \mathrm{~h}$ post a.m. milk feeding via jugular venipuncture into evacuated tubes containing EDTA for blood hematocrit (HEM), plasma total protein (PTP), and plasma $\beta$ HBA determination. Samples from wk 4, 5, and 6 were analyzed for plasma $\beta$ HBA using the Stanbio $\beta$-Hydroxybutyrate LiquiColor ${ }^{\circledR}$ kit (Procedure No. 2440; Stanbio Laboratory, Boerne, TX). The HEM and PTP for wk 0 to 6 were determined according to Naylor and Kronfeld (1977) and McBeath et al. (1971), respectively.

\section{Rumen Tissue Sampling}

A subset of 6 male calves (2 per treatment) was euthanized at 6 wk of age using captive bolt stunning and exsanguination. Digestive tracts were harvested, emptied, and rinsed with cold water, and rumen tissue samples were collected for analysis of papillae length $(\mathbf{P L})$, papillae width (PW), and rumen wall thickness (RWT) according to Lesmeister et al. (2004). An additional set of 6 male calves ( 2 per treatment) was randomly assigned to treatments and euthanized at $5 \mathrm{wk}$ of age to investigate a yeast culture effect on extent of rumen development at weaning. Similar rearing procedures and tissue sample collection were used.

\section{Statistical Analyses}

Data for intake, growth, and blood parameters were analyzed as a randomized complete block design with 25 blocks; rumen development data were analyzed as a completely randomized design. A repeated measures analysis was conducted using the MIXED procedure of SAS (1999), with block and calf utilized as the random effect for the growth and rumen development analyses, respectively. Differences were noted at $P<0.05$ and $P$ $<0.10$ for the growth and rumen development analyses, respectively. The statistical model utilized for analyses was

$$
\mathrm{z}_{\mathrm{ytc}}=\mu+\alpha_{\mathrm{y}}+\beta_{\mathrm{t}}+(\alpha \beta)_{\mathrm{yt}}+\mathrm{e}_{\mathrm{ytc}}
$$

where

$\mathrm{z}_{\mathrm{ytc}}=$ observed values for BW, DMI, FE, hip height, withers height, hip width, heart girth, HEM, PTP, $\beta$ HBA, PL, PW, or RWT taken from the calf c receiving the level of yeast culture $y$ at time t;

$\mu=$ overall mean of the population;

$\alpha_{\mathrm{y}}=$ fixed effect of level of yeast culture $\mathrm{y}$ where $\mathrm{y}=$ 0,1 , or $2 \%$ supplemental yeast culture;

$\beta_{\mathrm{t}}=$ random effect of the measurement taken at time $\mathrm{t}$ where $\mathrm{t}=1$ to $42 \mathrm{~d}$ for intake analysis; 0 to 6 wk for growth, HEM, and PTP analyses; 4 to 6 wk for plasma $\beta$ HBA analysis; and wk 5 or 6 for rumen development analysis;

$(\alpha \beta)_{\mathrm{yt}}=$ effect of the interaction between level of yeast culture y and the measurement taken at time $\mathrm{t}$; and

$\mathrm{e}_{\mathrm{ytc}}=$ error associated with the measurement taken from calf $\mathrm{c}$ receiving level of yeast culture $\mathrm{y}$ at time t, $e_{y t c} \approx N\left(0, \sigma_{e}^{2}\right)$.

Birth weight was included in the model as a covariate for pre-weaning and overall ADG analyses, and weaning weight was the covariate for post-weaning ADG analysis. Initial measurements for hip height, withers height, heart girth, and hip width were included in the model as covariates for their respective analyses. For the HEM analysis, PTP was included as a covariate. Average overall starter DMI was utilized as a covariate for all rumen development analyses. A sex effect was included in all models except for rumen development, but was not significant. 
Table 3. Pre- and postweaning least square means for intake and BW of Holstein calves receiving 0 (control), 1 (1YC), or $2 \%$ (2YC) supplemental yeast culture in a texturized calf starter.

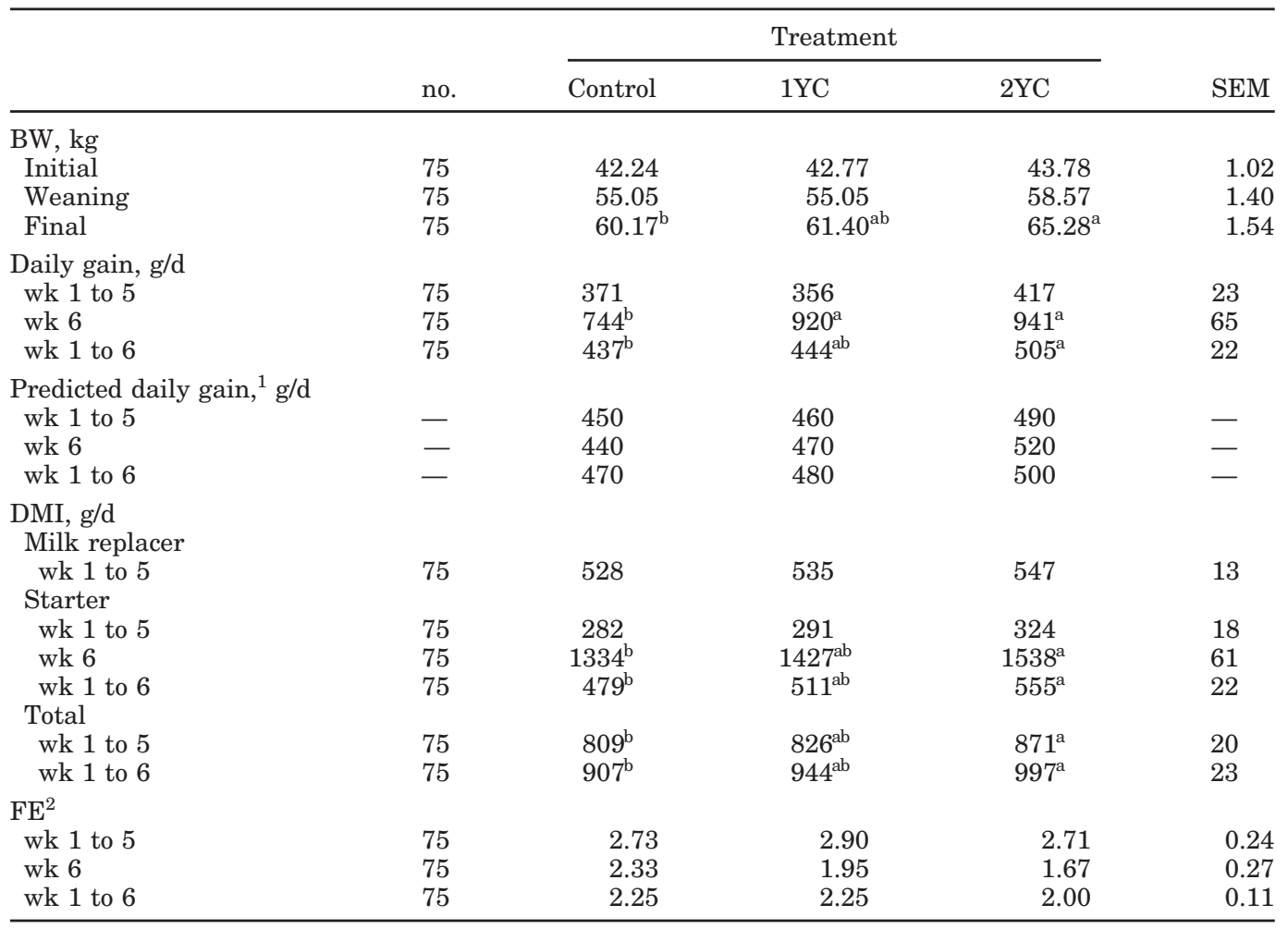

${ }^{\mathrm{a}, \mathrm{b}}$ Means within a row without common superscripts are different at $P<0.05$.

${ }^{1}$ Predicted using NRC (2001).

${ }^{2} \mathrm{FE}=$ Feed efficiency; expressed as kg of feed:kg of gain.

\section{RESULTS AND DISCUSSION}

\section{Intake and BW Gain}

Table 3 presents least squares means for initial, weaning, and final BW; ADG; FE (feed:gain); and milk replacer, starter, and total DMI. Values for ADG, DMI, and $\mathrm{FE}$ are presented for pre-weaning (wk 1 to 5), postweaning (wk 6), and overall (wk 1 to 6 ) periods. Initial BW and, therefore, milk replacer DMI were not significantly different between treatments. In addition, $\mathrm{FE}$ prior to weaning was not significantly influenced by adding yeast culture to the starter ration. Starter DMI for calves receiving $2 \mathrm{YC}$ starter tended to be higher prior to weaning $(P=0.07)$ and was significantly higher post-weaning $(P<0.02)$ and overall $(P<0.01)$ when compared with control calves; starter DMI in calves fed 1YC starter was intermediate but not statistically different from either control or 2YC. Total DMI (milk + starter) for $2 \mathrm{YC}$ calves was significantly higher prior to weaning $(P<0.02)$ and overall $(P<0.01)$ than that for control calves and tended $(P=0.08)$ to be higher for $2 \mathrm{YC}$ than for $1 \mathrm{YC}$ calves during the same periods. Results for DMI from the current study partially sup- port the findings of Quigley et al. (1992), who found numerically increased starter and total DMI prior to weaning. Conversely, significantly higher starter and total DMI for calves receiving $2 \mathrm{YC}$ starter post-weaning and overall in the current study are in contrast to the results of Quigley et al. (1992), who indicated a significant decrease in DMI post-weaning and overall with supplemental yeast culture. However, the yeast culture content for $2 \mathrm{YC}$ starter was greater by a factor of 10 in the current study in comparison with that incorporated in the Quigley et al. (1992) study. In addition, others have found decreased DMI when brewer's yeast (Seymour et al., 1995) or live yeast (Wagner et al., 1990) was added to calf diets. Williams et al. (1991) indicated that yeast culture beneficially alters conditions detrimental to cellulolysis, thereby possibly influencing intake. No forages were offered to calves in this study; therefore, the possible effects of yeast on cellulolysis likely remained unexploited.

Average daily gain prior to weaning was not significantly different between treatments but tended $(P=$ 0.06 ) to be higher for calves receiving $2 \mathrm{YC}$ starter than for calves receiving $1 Y C$ starter. However, ADG post- 
weaning was significantly $(P<0.05)$ higher for calves receiving supplemental yeast culture than for control calves. Overall, ADG was significantly $(P<0.05)$ higher for $2 \mathrm{YC}$ calves than for control calves and tended $(P=$ 0.05 ) to be higher for calves receiving $2 \mathrm{YC}$ starter than for calves receiving $1 \mathrm{YC}$ starter. Increased overall $\mathrm{ADG}$ for $2 \mathrm{YC}$ calves resulted in a tendency $(P=0.08)$ for higher weaning $\mathrm{BW}$ in calves receiving $2 \mathrm{YC}$ starter when compared with control and 1YC calves. In addition, final BW was significantly $(P<0.03)$ greater for calves receiving $2 \mathrm{YC}$ than for control calves and tended $(P=0.08)$ to be greater for calves receiving $2 \mathrm{YC}$ starter than for calves receiving $1 \mathrm{YC}$ starter. Calves receiving $2 \mathrm{YC}$ starter tended $(P=0.07)$ to require less feed per $\mathrm{kg}$ of BW gain than control calves post-weaning. A tendency $(P=0.09)$ for increased $\mathrm{FE}$ was also observed for $2 \mathrm{YC}$ calves when compared with control and $1 \mathrm{YC}$ calves on an overall basis. Calves fed starter containing brewer's yeast (Seymour et al., 1995) or a low level of live yeast (Wagner et al., 1990; Quigley et al., 1992) have not exhibited increased ADG in previous studies; however, dietary inclusion levels were higher, and yeast product tested was different, in the present study. Increased ADG observed in the current study may also be attributed to a residual effect of increased starter DMI and, therefore, increased gut fill.

Observed ADG from the current study was compared against predicted values for ADG calculated using NRC (2001). However, differences between actual and predicted values must be interpreted carefully, especially for post-weaned ruminant calves weighing $<100 \mathrm{~kg}$ because of age, diet, and BW differences between calves in the current study and calves contained within the NRC (2001) data. The NRC (2001) indicated a void in the literature for calorimetric and/or comparative slaughter research conducted with weaned, ruminant calves weighing $<100 \mathrm{~kg}$. In addition, Blaxter (1967) indicated decreases in utilization efficiencies of energy and protein for growth as calves aged, and BW and fat deposition increased as the diet changed. Therefore, comparisons of observed and predicted ADG are likely only valid for pre-weaned calves from the current study. However, because of the current popularity of alternative calf feeding programs (i.e., accelerated growth, early weaning) and the concomitant possibility for altered weaning age and diet with these new programs, results for predicted ADG during the post-weaning and overall period are included in an effort to stimulate future research (Table 3).

Average daily gain for all treatments during the preweaning period and for calves receiving the control and 1YC starter overall were lower than predicted by the model. However, actual post-weaning ADG was higher for all treatments than predicted by the NRC (2001) model. Lower actual pre-weaning and overall ADG may indicate an inefficient utilization of protein and energy present in a ration containing milk replacer and starter or that the NRC (2001) model over-predicts ADG when milk replacer is included in the ration. In contrast, higher actual post-weaning ADG may indicate more efficient utilization of starter nutrients than predicted by the NRC (2001) model. However, as stated earlier, comparisons between actual and predicted ADG for the post-weaning and overall periods must be interpreted carefully and may not be valid because of weaning age, BW, and dietary differences between the current study data and NRC (2001) data.

\section{Structural Growth}

Least squares means for initial, final, and average daily change of hip height, withers height, hip width, and heart girth are presented in Table 4 . There were no significant treatment differences for initial structural growth measurements or final hip height and wither height. Average daily hip height change was $(P<0.03)$ greater for calves receiving $2 \mathrm{YC}$ starter than for calves receiving $1 \mathrm{YC}$ starter. Average daily withers height change for $2 \mathrm{YC}$ calves was significantly greater than that for controls $(P<0.01)$ and tended to be greater than 1YC $(P=0.09)$ calves, resulting in $2 \mathrm{YC}$ calves having a significantly greater $(P<0.05)$ final hip width than control calves and a tendency for greater final hip width in $2 \mathrm{YC}$ than in $1 \mathrm{YC}(P=0.05)$ calves. Final heart girth for calves receiving $2 \mathrm{YC}$ starter tended $(P=0.05)$ to be greater than that for control calves because of a tendency $(P=0.09)$ for higher average daily heart girth change for $2 \mathrm{YC}$ calves than for control calves. In addition, final heart girth for calves receiving $2 \mathrm{YC}$ starter was significantly $(P<0.04)$ greater than that for $1 \mathrm{YC}$ calves. Increases in daily hip width and heart girth changes for calves receiving $2 \mathrm{YC}$ starter when compared with control calves may indicate increased body capacity, subsequently resulting in the observed differences for DMI and ADG between these 2 treatments (Van Soest, 1994; Forbes, 1995). Mir and Mir (1994) indicated that yeast culture resulted in a numerical increase in carcass weight but a decrease in meat yield, possibly suggesting a yeast culture effect on bone growth. Increased structural growth in calves receiving 2YC starter may be the result of additional energy and nutrients available for skeletal deposition due to the observed increase in starter DMI for $2 \mathrm{YC}$ calves. However, this occurrence is not certain because of the limited indication of a yeast culture influence on structural growth, in mature or immature ruminants, in the literature. 
Table 4. Least squares means for structural growth measurements for Holstein calves receiving 0 (control), 1 (1YC), or $2 \%$ (2YC) supplemental yeast culture in a texturized calf starter.

\begin{tabular}{|c|c|c|c|c|c|}
\hline & \multirow[b]{2}{*}{ no. } & \multicolumn{3}{|c|}{ Treatment } & \multirow[b]{2}{*}{ SEM } \\
\hline & & Control & $1 \mathrm{YC}$ & $2 \mathrm{YC}$ & \\
\hline \multicolumn{6}{|l|}{ Hip height } \\
\hline Initial, $\mathrm{cm}$ & 75 & 79.71 & 79.43 & 79.48 & 0.58 \\
\hline Final, cm & 75 & 86.08 & 85.60 & 86.46 & 0.61 \\
\hline Change, $\mathrm{cm} / \mathrm{d}$ & 75 & $0.15^{\mathrm{ab}}$ & $0.14^{\mathrm{b}}$ & $0.17^{\mathrm{a}}$ & 0.01 \\
\hline \multicolumn{6}{|l|}{ Wither height } \\
\hline Initial, $\mathrm{cm}$ & 75 & 76.25 & 76.33 & 76.51 & 0.53 \\
\hline Final, cm & 75 & 82.55 & 82.32 & 83.13 & 0.53 \\
\hline Change, $\mathrm{cm} / \mathrm{d}$ & 75 & 0.15 & 0.14 & 0.16 & 0.01 \\
\hline \multicolumn{6}{|l|}{ Hip width } \\
\hline Initial, cm & 75 & 18.09 & 17.91 & 18.06 & 0.16 \\
\hline Final, cm & 75 & $20.27^{\mathrm{b}}$ & $20.30^{\mathrm{ab}}$ & $20.78^{\mathrm{a}}$ & 0.18 \\
\hline Change, $\mathrm{cm} / \mathrm{d}$ & 75 & $0.05^{b}$ & $0.06^{\mathrm{ab}}$ & $0.06^{\mathrm{a}}$ & $<0.01$ \\
\hline \multicolumn{6}{|l|}{ Heart girth } \\
\hline Initial, cm & 75 & 77.17 & 77.27 & 77.80 & 0.70 \\
\hline Final, cm & 75 & $86.87^{\mathrm{ab}}$ & $86.72^{\mathrm{b}}$ & $88.93^{\mathrm{a}}$ & 0.74 \\
\hline Change, $\mathrm{cm} / \mathrm{d}$ & 75 & 0.23 & 0.23 & 0.26 & 0.01 \\
\hline
\end{tabular}

${ }^{\mathrm{a}, \mathrm{b}}$ Means within a row without common superscripts are different at $P<0.05$.

\section{Blood Parameters}

There were no treatment effects for blood parameters measured over time; therefore, Table 5 presents overall least squares means for HEM, PTP, and plasma $\beta \mathrm{HBA}$ concentration. These values are consistent with expected values for calves of this age, and no treatment differences were observed for HEM, PTP, or $\beta$ HBA. Quigley et al. (1992) reported a significantly increased $(P<0.01)$ plasma $\beta \mathrm{HBA}$ at $4 \mathrm{~h}$ after feeding and a significantly greater $(P<0.05)$ change in $\beta$ HBA from 0 to $4 \mathrm{~h}$. Blood samples were taken at approximately $4 \mathrm{~h}$ after feeding in the current study; however, pre- and post-feeding changes were not measured, and yeast culture effects on plasma $\beta$ HBA were not observed.

\section{DS}

Least squares means for DS are presented in Table 5. No treatment differences were observed for DS in the current study. Seymour et al. (1995) indicated a numerical, but nonsignificant, decrease in DS when brewer's yeast was included at $1 \%$, attributing these results to increased growth of beneficial gut microorganisms, establishment of normal gut fermentation, and subsequent reduction in stress and digestive upset. In addition, Cole et al. (1992) reported decreased morbidity and mortality rates and number of treated sick days when yeast culture was included in feeder calf diets. However, similar yeast culture influences were not observed in the current study, possibly because of low incidences of scouring across treatment groups.

\section{Rumen Development}

Least squares means for PL, PW, and RWT from calves utilized to determine the effects of yeast culture on rumen development parameters are presented in Table 6. No differences for rumen development parameters were observed between calves euthanized at 5 or 6 wk of age; therefore, Table 6 also includes results from combined analyses. There were no significant dif-

Table 5. Least squares means for blood parameter measurements and days scoured for Holstein calves receiving 0 (control), 1 (1YC), or $2 \%$ ( $2 \mathrm{YC}$ ) supplemental yeast culture in a texturized calf starter.

\begin{tabular}{llccc}
\hline & \multicolumn{3}{c}{ Treatment } & \\
\cline { 2 - 4 } & Control & 1 SC & 2 SEM \\
\hline Hematocrit $^{1}$ & 32.87 & 32.63 & 31.89 & 0.64 \\
Plasma total protein, g/dL $_{\beta \text { HBA, }}^{2}$ mmol/L & 5.14 & 5.06 & 5.22 & 0.07 \\
Days scoured & 0.167 & 0.157 & 0.173 & 0.011 \\
\hline
\end{tabular}

${ }^{1}$ Blood hematocrit volume as a percentage of whole blood.

${ }^{2} \beta \mathrm{HBA}=$ plasma $\beta$-hydroxybutyrate. 
Table 6. Least squares means for rumen development measurements for Holstein calves receiving 0 (control), 1 (1YC), or $2 \%$ (2YC) supplemental yeast culture in a texturized calf starter.

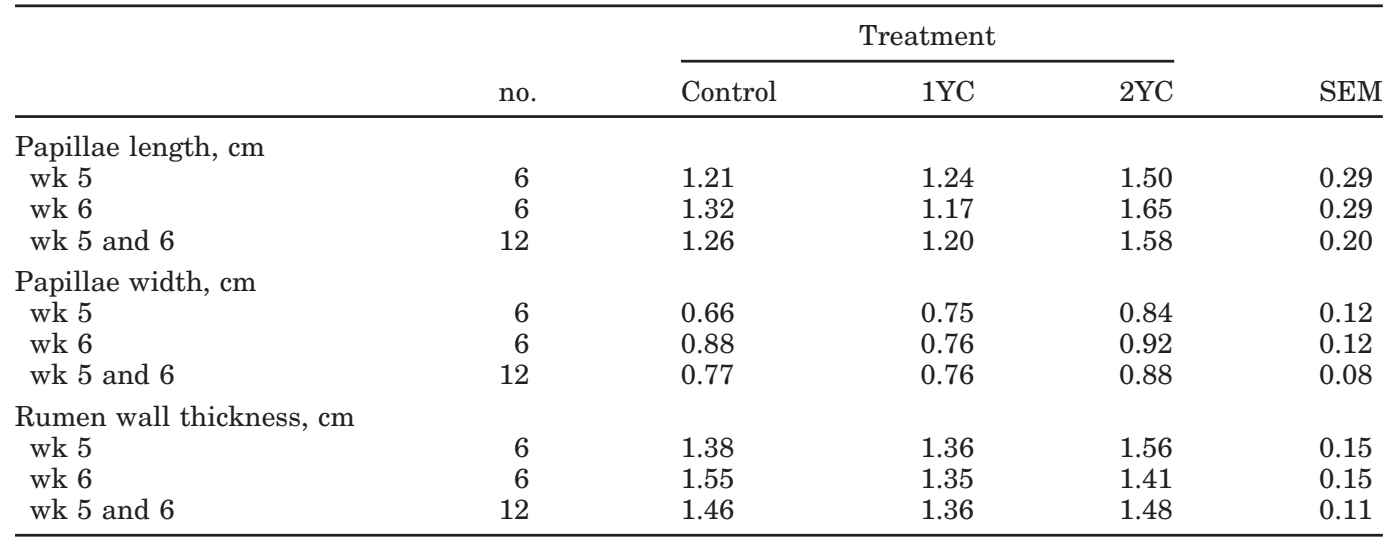

ferences between treatments for rumen development parameters at either age or with the combined analyses. However, at the time of weaning PL and PW were 19 and $21 \%$ greater, respectively, in calves fed $2 \mathrm{YC}$ starter than in calves receiving the control starter. In addition, the combined analyses indicated a 20 and $12 \%$ increase in $\mathrm{PL}$ and $\mathrm{PW}$, respectively, for $2 \mathrm{YC}$ calves compared with control calves. Previous rumen development research has reported dry ration effects on rumen development parameters but has focused on dietary physical form or dietary type (i.e., concentrates vs. forages) (Stobo et al., 1966; Nocek et al., 1984; Greenwood et al., 1997). Others have found age-related differences in rumen development parameters (Nocek et al., 1984; Klein et al., 1987; Zitnan et al., 1999). Rumen development appeared to increase slightly when calves consumed 2YC starter. Drawing definite conclusions of a yeast culture effect on rumen development at wk 5 or 6 for calves is difficult because of limited calf numbers (Lesmeister et al., accepted). However, the combined analysis should contain a sufficient number of calves (Lesmeister et al., accepted) and does indicate a slight increase in rumen development parameters when calves consumed $2 \mathrm{YC}$ starter.

\section{CONCLUSION}

Increases in starter and total DMI, $\mathrm{ADG}$, and daily hip height and hip width changes indicate a positive influence of yeast culture on dairy calf growth, especially at the $2 \mathrm{YC}$ inclusion level. However, increased $\mathrm{ADG}$ in calves receiving $2 \mathrm{YC}$ starter may be an effect of residual gut fill and/or increased bone growth. Calves receiving $2 \mathrm{YC}$ also exhibited a slight improvement in rumen development parameters. Furthermore, inclusion of yeast culture in calf starters did not negatively influence other parameters measured. Therefore, in- creased DMI, ADG, and the slight improvement in rumen development may warrant yeast culture inclusion in dairy calf starters. In addition, the results seem to indicate that increasing the level of dietary yeast culture may influence intake and BW gain in an additive fashion. Therefore, research determining the optimum yeast culture inclusion rate in dairy calf diets should be conducted.

\section{REFERENCES}

Association of Official Analytical Chemists. 1990. Official Methods of Analysis. 15th ed. AOAC, Arlington, VA.

Association of Official Analytical Chemists. 2000. Official Methods of Analysis. 17th ed. AOAC, Arlington, VA.

Blaxter, K. L. 1967. The Energy Metabolism of Ruminants. Rev. Ed. Hutchinson and Co. LTD., London, UK.

Bull, L. S., L. J. Bush, J. D. Friend, B. Harris, Jr., and E. W. Jones. 1965. Incidence of ruminal parakeratosis in calves fed different rations and its relation to volatile fatty acid absorption. J. Dairy Sci. 48:1459-1466.

Cole, N. A., C. W. Purdy, and D. P. Hutcheson. 1992. Influence of yeast culture on feeder calves and lambs. J. Anim. Sci. 70:1682-1690.

Flatt, W. P., R. G. Warner, and J. K. Loosli. 1958. Influence of purified materials on the development of the ruminant stomach. J. Dairy Sci. 41:1593-1600.

Forbes, J. M. 1995. Voluntary Food Intake and Diet Selection in Farm Animals. CAB International, Wallingford, Oxon, UK.

Erasmus, L. J., P. M. Botha, and A. Kistner. 1992. Effect of yeast culture supplement on production, rumen fermentation, and duodenal nitrogen flow in dairy cows. J. Dairy Sci. 75:3056-3065.

Greenwood, R. H., J. L. Morrill, E. C. Titgemeyer, and G. A. Kennedy. 1997. A new method of measuring diet abrasion and its effect on the development of the forestomach. J. Dairy Sci. 80:2534-2541.

Hinders, R. G., and F. G. Owen. 1965. Relation of ruminal parakeratosis development to volatile fatty acid absorption. J. Dairy Sci. 48:1069-1073.

Klein, R. D., R. L. Kincaid, A. S. Hodgson, J. H. Harrison, J. K. Hillers, and J. D. Cronrath. 1987. Dietary fiber and early weaning on growth and rumen development of calves. J. Dairy Sci. 70:2095-2104.

Krishnamoorthy, U., T. V. Muscato, C. J. Sniffen, and P. J. Van Soest. 1982. Nitrogen fractions in selected feedstuffs. J. Dairy Sci. 65:217-225.

Kumar, U., V. K. Sareen, and S. Singh. 1997. Effect of yeast culture supplementation on ruminal microbial populations and metabo- 
lism in buffalo calves fed a high roughage diet. J. Sci. Food Agric. 73:231-236.

Larson, L. L., F. G. Owens, J. L. Albright, R. D. Appleman, R. C. Lamb, and L. D. Muller. 1977. Guidelines toward more uniformity in measuring and reporting calf experimental data. J. Dairy Sci. 60:989-991.

Lesmeister, K. E., P. R. Tozer, and A. J. Heinrichs. Development and analysis of a rumen tissue sampling procedure. J. Dairy Sci. 87:1336-1344.

McBeath, D. G., W. J. Penhale, and E. F. Logan. 1971. An examination of the influence of husbandry on the plasma immunoglobulin level of the newborn calf, using a rapid refractometer test for assessing immunoglobulin content. Vet. Rec. 88:266-270.

Mir, Z., and P. S. Mir. 1994. Effect of the addition of live yeast (Saccharomyces cerevisiae) on growth and carcass quality of steers fed high-forage or high-grain diets and on feed digestibility and in situ degradability. J. Anim. Sci. 72:537-545.

Mutsvangwa, T., I. E. Edwards, J. H. Topps, and G. F. M. Paterson. 1992. The effect of dietary inclusion of yeast culture (YEA-SACC) on patterns of rumen fermentation, food intake, and growth of intensively fed bulls. Anim. Prod. 55:35-40.

Naylor, J. M., and D. S. Kronfeld. 1977. Refractometry as a measure of the immunoglobulin status of the newborn dairy calf: Comparison with the zinc sulfate turbidity test and single radial immunodiffusion. Am. J. Vet. Res. 38:1331-1334.

Nocek, J. E., C. W. Heald, and C. E. Polan. 1984. Influence of ration physical form and nitrogen availability on ruminal morphology of growing bull calves. J. Dairy Sci. 67:334-343.

National Research Council. 2001. Nutrient Requirements of Dairy Cattle. 7th rev. ed. Natl. Acad. Sci., Washington, DC.

Quigley, J. D., III, L. B. Wallis, H. H. Dowlen, and R. N. Heitmann. 1992. Sodium bicarbonate and yeast culture effects on ruminal fermentation, growth, and intake in dairy calves. J. Dairy Sci. 75:3531-3538.

Sander, E. G., R. G. Warner, H. N. Harrison, and J. K. Loosli. 1959 The stimulatory effect of sodium butyrate and sodium propionate on the development of rumen mucosa in the young calf. J. Dairy Sci. 42:1600-1605.

SAS User's Guide 2: Statistics, Version 8.01 ed. 1999. SAS Inst., Inc., Cary, NC.

Seymour, W. M., J. E. Nocek, and J. Siciliano-Jones. 1995. Effects of a colostrum substitute and of dietary brewer's yeast on the health and performance of dairy calves. J. Dairy Sci. 78:412-420.

Stobo, I. J. F., J. H. B. Roy, and H. J. Gaston. 1966. Rumen development in the calf. 2 . The effect of diets containing different proportions of concentrates to hay on digestive efficiency. Br. J. Nutr. 20:189-215.

Van Soest, P. J. 1994. Nutritional Ecology of the Ruminant. 2nd ed. Cornell Univ. Press, Ithaca, NY.

Wagner, D. G., J. Quinonez, and L. J. Bush. 1990. The effect of cornor wheat-based diets and yeast culture on performance, ruminal $\mathrm{pH}$, and volatile fatty acids in dairy calves. Agri-Pract. 11:7-12.

Williams, P. E. V., C. A. G. Tait, G. M. Innes, and C. J. Newbold 1991. Effects of the inclusion of yeast culture (Saccharomyces cerevisiae plus growth medium) in the diet of dairy cows on milk yield and forage degradation and fermentation patterns in the rumen of steers. J. Anim. Sci. 69:3016-3026.

Yoon, I. K., and M. D. Stern. 1996. Effects of Saccharomyces cerevisiae and Aspergillus oryzae cultures on ruminal fermentation in dairy cows. J. Dairy Sci. 79:411-417.

Zitnan, R., J. Voigt, J. Wegner, G. Breves, B. Schroder, C. Winckler, M. Levkut, M. Kokardova, U. Schonhusen, S. Kuhla, H. Hagemeister, and A. Sommer. 1999. Morphological and functional development of the rumen in the calf: Influence of the time of weaning. Arch. Anim. Nutr. 52:351-362. 